\title{
Tutoring English Language Learners: Practices that Work
}

\author{
Sarah R. Edwards Moore \\ Susquehanna University, United States
}

\begin{abstract}
There is a significant number of adolescent English Language Learners (ELLs) who are struggling in school. Tutoring programs are being implemented to help ELLs. This case study examines three practices tutors used when working with adolescent English Language Learners (ELLs) in one-on-one sessions. The practices used, modeling, translation, and partnership proved to effectively support academic progress within the session. The research work contributes significantly to the work of tutors and educators who work with struggling ELLs.
\end{abstract}

\section{Introduction}

The United States Department of Education reported in 2010-2011 that nearly half the states graduated less than $60 \%$ of students with a limited proficiency in English. Pennsylvania, the site of my study, has an ELL graduation rate of $63 \%$ compared with Vermont and South Dakota that have the highest graduation rate, at $82 \%$. Arizona has the lowest graduation rate, at $25 \%$. In light of this report, it is not surprising that ELLs accounted for the highest population of high school dropouts in United States public schools U.S. Census Bureau [1]. The U.S. Census Bureau [1] reported that the highest percentage $(13 \%)$ of ELL students who drop out of high school are Hispanic students. The National Center for Education Statistics [2] noted that $51 \%$ of Hispanic identified high school dropouts reported having difficulty speaking English, compared to $18 \%$ who reported speaking English well. August [3] further concluded after conducting an extensive literacy review on secondary ELLs that "[s]uccessful completion of high school is associated with the ability to speak English" (p. 24).

\section{Literature Review}

One of the several strategies that is being used to support adolescent English Language Learners is the implementation of tutoring programs. With the high school dropout rate increasing, it is important to conduct preventive interventions with student populations who are at risk of not only failing in school, but continuing to have difficulties as a result of school failure. Dynarski and Gleason [4] reviewed programs that reduced the rate of high school dropouts and identified that the successful programs that helped to reduce the dropout rate were done with middle school students and younger students. The programs that were successful focused on specific students and had targeted goals. Even with the above findings reporting that schools see great promise in tutoring programs for middle school students, there has been little research that tutoring programs work beyond the early grades.

There is almost no research available on the effectiveness of tutoring programs with high school students. This is concerning considering that Joftus and Maddox-Dolan [5] reported that in the U.S., roughly six million secondary students read below grade level and 3,000 students drop out of high school every day. The secondary years provide the last chance for many students to succeed in their demanding courses Biancarosa and Snow, [6] Joftus and MaddoxDolan [5].

As stated above, little research has been done on the effectiveness of tutoring programs, but programs that are focused on reading instruction for middle and high schools are being more widely implemented (Deshler et al., [7]) due to accountability standards set by legislation like No Child Left Behind (NCLB). It would benefit ELLs if more studies looked at how tutoring sessions are currently being structured for ELLs and what factors contribute to their academic success. This study investigated a practice that three tutors used in their work with adolescent ELLs in oneon-one tutoring sessions which contributed to academic success. The following research question guided the study:

1. Are there any specific practices that volunteer tutors in one-on-one tutoring sessions with at-risk adolescent ELLs use to encourage academic success? 


\section{Methods and Methodologies}

The site for this study was an urban charter school, located in the state of Pennsylvania. Pennsylvania public schools currently serve 42,542 ELLs that speak 175 different languages. Spanish is the most frequently spoken first language (L1) among the ELL population. Every school district and charter school is required under Title 22, Chapter 4, Section 4.26 of the Curriculum Regulations to provide a program for every ELL student. In order to comply, school districts must provide ELL students with a planned program of instruction that is appropriate to the student's development and instructional level. The charter school campus that was selected used the service of volunteer tutors as part of its documented program of support to help ELLs. I chose this site because currently, $19 \%$ of the school's population is comprised of ELL students and they were instituting a one-on-one volunteer tutoring program for seven weeks in order to help their ELL population. The charter school campus included a middle school, high school, and Cyber School.

The purposeful sample for this case study included three volunteer tutors and 34 at-risk secondary ELLs who identify themselves as Hispanic. The tutors were given pseudonyms and are called Hannah, Pete, and Molly throughout the study. All three of the tutors were enrolled in a pre-service education program at an urban university in Pennsylvania.

This section details the data collection methods this case study employed. The main source of data was observations followed by interviews and tutoring reflection logs. Interviews were conducted with each tutor. The tutors were interviewed before the study began and after the study concluded. The tutors also filled out reflection logs after each tutoring session. Tutors were observed over a 7 -week time period and each tutor was observed conducting 20 sessions.

The data collected was analyzed using open coding. Modeling, Translating, and Partnership were the open codes that emerged as the practices tutors used within sessions that helped students progress academically. The codes were applied across the observational, interview, and tutoring reflection log data. Trends were noted and will be reported in the results section.

\section{Analysis of Findings}

The results of this study indicated that three key practices; modeling, translation, and partnership were used by tutors in sessions which influenced academic progress. Below the practices are described using examples from the interviews, observations, and tutoring reflection logs. As stated in the Methods section, the three tutors are referred to as Molly, Hannah, and Pete.

\section{Modeling}

The tutors interacted with students using modeling in one-on-one sessions. Modeling is being defined as the tutors first showing the students how to do something in the session or the tutors would show the students how to think about something before they would ask the students to independently practice a skill. Modeling was identified by all of the tutors in their final interviews as a tool they all recognized they used in sessions. Molly referred to modeling when she talked about helping one student understand the mathematical concept of intercepts. She said, "I explained to her how to find the y-intercept and modeled with a simple example and she suddenly completely understood and was able to complete the rest of the worksheet with ease" (Post-interview, 1-32014). Pete referred to modeling when he talked about how he ran each session. He said, "I would model in each one-on-one interaction and part of modeling was bringing my pen and notebook to each session" (PostInterview, 12-28-2014). Hannah attributes her modeling to knowing the material. She said, "If I really knew the concept we were working on, I was able to model more confidently and my students would be able to do the work independently when it was time" (Post-Interview, 12-27-2014).

Although modeling was used in many ways, there is one key way that each of the tutors demonstrated modeling throughout their sessions: they would model for students how to go about answering questions in order to demonstrate comprehension in reading and math on multiple choice assessments. Below, examples of how each tutor modeled answering comprehension questions in sessions are shared.

Molly

Several of the students Molly worked with would come to her tutoring sessions in hopes of preparing for an exam they had coming up. Throughout these sessions, Molly would choose to model for how to find an answer or navigate an exam. For example, during a session where Molly was helping a student with prepping for the SAT exam, Molly modeled for the student how to go through each answer choice to pick an answer. Molly would look at the passage and then look back at the answer. During this process, she would explain to the student what she was doing in order to decide what answer she would go with (Observation, 12-1-2015). 
In the reflection log that Molly filled out at the end of the session, she referred to how modeling how to navigate the reading passages seemed to support the session. Molly wrote, "This session was challenging to the student and a little frustrating. The student is nervous for the test, especially if it is all in English. When I would model reading the passages and explain them, the student understood a lot better" (Reflection Log, 12-1-2015).

\section{Hannah}

Like Molly, Hannah would have several students come to her sessions in order to work with content that was helping them get prepared for taking an upcoming standardized test. The students would typically bring a reading passage that had comprehension questions attached to it and would ask Hannah to help them figure out how to complete the questions associated with the reading. During these sessions, Hannah would use modeling in order to demonstrate for the student how to read a text in order to find information. Below is an example of how her method of modeling would happen in a session.

Hannah was helping a student understand an article about the man who invented Hoover Vacuums. The article was in interview format and the student told Hannah that he needed to answer the questions that were at the end of the article. Hannah made a decision to model how to accomplish the task. She first modeled reading over the questions and then went back to the beginning of the article and read it out loud after asking the student if he wanted to listen to her read or read the article on his own. When reading the article, Hannah would stop to enunciate, track, and think aloud about how what she was reading might fit into one of the questions being asked at the end of the reading. Hannah modeled how to read for information on two of the questions and then asked the student to use the strategy in order to answer the remaining three questions. The student practiced what Hannah had just modeled and she would reiterate any modeling techniques that the student did not remember as they worked to complete the article (Observation, 11-102015).

In her reflection log Hannah felt that the session went well due to the modeling method she used. Hannah writes, "The session went better than my first session which makes me super happy because I did not think he got much out of the first session we had together. Today, we did a different method where I would model reading to him and summarizing before having him try it" (Reflection Log, 11-10-2014).
Pete

Unlike Molly and Hannah, Pete would model how to answer math comprehension questions rather than reading comprehension questions for students. Many of Pete's sessions involved working with students at the Cyber School on a variety of Math skills. Students would come to a session with Pete and need help working through an end of a lesson assessment. The assessments would typically have a Math problem and four possible answer choices from which the student would pick the best answer choice. Below is an example of how Pete chose to model how to work through a Math question in order to answer assessment questions.

Pete was working with a student at the Cyber School on a lesson assessment based on geometric angles. The computer lesson would present a question and four possible answer choices. The student started out guessing what answer may be right. Pete chose to model working out the problem in his notebook first in order to avoid a guessing game and instead modeled the process of finding the answer in his notebook first and then went back to the computer screen to see if it matched with any choices. After a few questions were modeled in this way the student started to write the problem down first, work it out, and then see if their answer matched any of the computer screen options (Observation, 11-14-2014).

In Pete's reflection log of the session, he said "This was the second time I have worked with this student and he rushes through problems and has a hard time staying on task. I wanted him to stay on task and explain the concepts behind each procedure of his math problem" (Reflection Log, 11-14-2014). Even though Pete did not call it modeling, it is apparent based on the actions Pete took during the session that he used a modeling technique to help the student think more about the procedures of math and not rush to answer problems on the assessment.

\section{Translation}

Tutors became translators when they used the student's first language and broke down English words or concepts in the sessions. The tutors would function as translators in two important ways. First, two tutors would use the student's first language or visuals to help students connect to English content in the session. Hannah and Molly chose to use what limited Spanish they knew to help direct students within their sessions and make the students more comfortable with English concepts. Molly and Hannah recognized the benefit of embracing the student's first language, even in a limited way, in their final interviews. Molly said, "I have little experience with Spanish, not a lot, but 
speaking in Spanglish felt silly to me and I thought they might make fun of me, but it was actually helpful to them. The students were actually excited when I would say something in Spanish because they felt they were teaching them as I was teaching them" (PostInterview, 1-3-2015). Hannah said, "I found that when I used simpler language or anytime I was able to throw Spanish into my session, even though I really don't know hardly any at all, even using a little bit helped. Sometimes I would use a broader Spanish term to define something or be able to use words that were similar in Spanish; general words in Spanish that would help them connect with English concepts" (Post-Interview, 12-27-2014).

Second, all of the tutors would function as translators based on how they would rephrase, simplify, and break down content in the sessions. In regards to simplifying material for students, each of the tutors mentioned this either in there pre or postinterviews. Pete said in his post-interview, "With my higher level ELLs in the Cyber School, I didn't really have to rephrase my language that much, but with my lower level ELL students at the high school, I used a lot of rephrasing" (Post-Interview, 12-28-2014). Hannah said in her post-interview, "I would use a lot of different strategies with my lower level ELLs at the high school. I would rephrase, read to them, and after reading I would summarize what was read back to them. If I felt the ELL was not giving enough of a summary, I would ask them a simpler question" (PostInterview, 12-27-2014). Molly said in her postinterview, "It was very different working with ELL students and I enjoyed it a lot. It made it easier to communicate with them when I would over-exaggerate my speech and talk with my hands a lot. I focused mainly on reading the directions to them and telling them in my words" (Post-Interview, 1-3-2015). Below, examples of how the tutors were translators in their sessions will be shared. First, examples of how Hannah and Molly would use Spanish in sessions will be discussed and then an example of how each of the tutors would translate content in a session by breaking it down, simplifying, or rephrasing with be shared.

\section{Molly}

Molly would translate content and connect with some of her students by using their first language, Spanish. This type of Spanish to English translation would tend to happen towards the beginning of a session when Molly was helping her students with gaining access to new material. Below is an example of how Molly would use Spanish in order for her students to connect with English concepts. Molly is working with a student on calculus concepts. This is the first time Molly has met with the student and the student has brought a computer translator to the session in order to help her and Molly communicate. The student and Molly work through the session using the translation device and Molly also decides to translate some of the English terms into Spanish as well. By the end of the session, the student leaves with a greater understanding of Calculus terms (Observation, 11-10-2014).

In her reflection log of the session Molly writes, "The student struggled with her English, but had a lot of understanding with math concepts. The computer translator helped us a lot with communication, especially with math terms." Molly does not mention her own influence in the session with helping the student move forward by using Spanish terms even though it is evident that this helped the session progress. She does make reference to how being able to interact with the translation tool in the session made a difference. Molly would use the translation computer program as an additional strategy to help her student understand and English concept.

Molly would also use the translation strategies of breaking things down, simplifying, or rephrasing English content in order for her ELL students to connect to concepts in a session. Below is an example of how Molly demonstrated translation through simplification. Molly is helping a student complete a project about animals for their ESL class. The student is unsure about how to do the assignment and tells Molly that she does not understand the English directions. Molly chooses to use translation strategies in the session. She reads the directions to the student, breaks them down into simple conversational phrases and then uses a pencil to draw out a picture that explains the directions she just gave orally. The student moves forward with the project by the end of the session (Observation, 11-24-2014).

Molly wrote in her reflection log, "The session went well, the student completed a lot of work she did not do on the animal presentation." Although Molly does not mention using any translation strategies in her reflection $\log$, it is obvious that her ability to break down English directions for her student helped the student progress in the session.

\section{Hannah}

Like Molly, Hannah would use Spanish terms when she was working with some of her students at the high school. The students she would work with at the high school were lower level ELL students and would usually bring content associated with reading comprehension to the session. Below is an example of how she would help the student translate the English content by navigating it with a Spanish term. Hannah is working with a student for the second time at the 
high school. The student has brought a reading passage and questions that she has to answer in English. Hannah begins to help the student navigate through the text heavy passage and Hannah thought it was important to stop and see if the student understood the English term, bigger. Hannah translated the English term by using the Spanish word for bigger, grande. As a result of this splash of Spanish in the session, the student was able to connect more with the text and understand what a comprehension question was asking for (Observation, 12-8-2015).In the reflection log of the session Hannah commented on the challenge of the session and how she tried to use different strategies. She does not specifically mention using the student's first language as a strategy but as evidenced above, translation in the session happened and seemed to make a difference in the student's attitude towards the material. Hannah said, "I think the session was challenging for my student because she knows such limited amounts of English. I was having a hard time trying to think of strategies to get her to understand what was being read and what she had to do for the teacher" (Reflection Log, 12-8-2015).

In some of her other sessions, Hannah would demonstrate translation strategies in how she would break down the material for her students. Below is an example of how Hannah would translate by breaking down an English concept for her student. Hannah is working with a student on understanding a social studies lesson. The social studies lesson deals with German history and Hannah decides to help the student understand some of the English content through a variety of translation strategies. Hannah uses hand gestures to explain the content of the story and provides the student with a synonym and an antonym of a comprehension question. At the end of the session, the student had completed all the questions associated with the passage (Observation, 11-102014).

In the reflection $\log$ of the session, Hannah recognized how she used different strategies that helped translate the English content. She writes, "The session went quick but went well. My student came to the session with a specific unit that she needed help with. All she needed was better clarifications and rephrasing of some of the English to understand the questions or passages. She left happy and I was happy to have helped" (Reflection Log, 11-14-2014). It is obvious from the above example how Hannah became a translator within the session by being able to clarify, break down, and rephrase English concepts.

Pete

As stated previously, Pete did not use Spanish to help his students understand concepts in English. He did translate English content in the session by simplifying it for his students. Below is an example of how Pete would use translation strategies. Pete is helping a student today on her Math coursework. The work involved radicals and exponents. The student has a hard time understanding the English terms exponents, bases and powers, and multiplying positive and negative numbers. The student also needed support understanding the relationship between radicals and exponents. Pete used a variety of translation strategies to support the session. He introduced each concept by drawing it on his notebook and then uses the drawing to support what he was explaining orally. At the end of the session, the student was able to demonstrate their understanding of the Math concepts by completing problems on their own (Observation Notes, 11-10-2014).

In his reflection log, Pete said:

I was overwhelmed at the beginning of the session because I realized that the student did not have a very strong foundational knowledge of English Math concepts and their relation to each other. The idea I emphasized most was the relationship between radicals and exponents. I also had to explain the terms related to exponents, bases and powers, as well as multiplying positive and negative numbers. At the end of the session, I think we both felt accomplished. I was proud of my student for being persistent and willing to learn (Reflection Log, 11-10-2014).

Pete took the time to translate several English Math concepts in the session in order for his student to have success. He broke down concepts and showed their relationships and meanings through guided visuals.

\section{Partnership}

The results of this study indicated that one key practice, partnership, was used by tutors in sessions which influenced academic progress. Below the partnership practice is described using examples from the interviews, observations, and tutoring reflection logs. The results are organized according to each individual tutor and as stated previously the tutors' names for purposes of this paper are Molly, Hannah, and Pete.

The tutors interacted as partners in their sessions. Partnership was defined when tutors negotiated, shared authority, and collaborated with students, teachers, and other students in the sessions. It was evident in preand post- interviews with tutors that establishing a partnership with not only students, but other stakeholders was important. Molly reflected, "I would ask the teacher for support in order to figure out how to help the students who were having difficulty understanding English" (Post-Interview, 1-3-2015). Pete commented in his pre-interview, "I think I would want everyone on the same page; teachers, tutors, and students. I think it would be good if we could decide 
where we want the students to be together" (PreInterview, 10-1-2014). In his post-interview, Pete explained, "A benefit of tutoring was helping students connect the dots" (Post-Interview, 12-28-2014). In her pre-interview Hannah commented, "I wouldn't want my students to think that they were looking up to me. I would want them to look at me as someone who was trying to help them out. I would also have an attitude that we can work through what they bring to the session together. I would seek support" (PreInterview, 10-2-2014). In her post-interview, Hannah said, "I liked being able to learn with the students and it was nice having Pete to ask questions about material I was unfamiliar with" (Post-Interview, 12-27-2014).

The tutors chose to build a partnership with students, teachers, and each other. One key way that all of the tutors demonstrated building a partnership with others was by sharing authority and collaborating. The tutors would ask other tutors or a teacher for help. They would also ask the students to help explain a concept to them or let the students know that they were learning the material right along with the student. Below is an example from each tutor on how they demonstrated establishing a partnership in the tutoring session in order to help the students.

\section{Molly}

Molly chose to collaborate with her students and share authority in several of her sessions. Molly was conducting many other one-on-one sessions within the context of a pull-in environment where the teacher was present and other students. The pull-in environment, as discussed in the previous chapter, was a classroom space that Molly became a part of. She would conduct one-on-one tutoring sessions within the larger context of a resource room and ESL class that was supported by an ESL teacher. Sometimes, the students that were present in the class would also be working on the same material that Molly was working in a one-on-one session. Below is an example that demonstrates how Molly partnered with other people in the room as she was conducting a session.

Molly was working with a student on calculus terms, specifically how to find the range, domain, and radiant. The student told Molly that she had a quiz on the concepts in the next class and Molly tried to help the student even though she had not worked with the calculus terms for a long time. Molly asked the student to see her binder, told her she has not worked with calculus since $11^{\text {th }}$ grade, and then resorted to asking another student in the class to explain the concepts in order to help Molly understand how to help the student. Molly was eventually able to help her student complete a few problems but told the student that she should check with her teacher on whether the problems are right (Observation, 11-21-2014).

In her reflection log, Molly wrote, "This was challenging because it was hard for me to remember a lot of the math work the student was doing. We were able to work through a lot of the work together and figure out how to solve the problems. (Reflection Log, 11-21-2014)

Although Molly did not explicitly say that she "partnered" with the student, she demonstrated through her actions in the session and in her reflection $\log$ that the reason she was able to help the student move forward was because she worked together with the student. She also did not mention asking another student for support but the decision to do so in the session enabled her and the student to work together.

\section{Hannah}

Unlike Molly, Hannah conducted the majority of her one-on-one tutoring sessions in a pull-out environment. The pull-out environment, as explained in the previous chapter, was a separate room within the Cyber School or High School where the tutors would meet one-on-one with their students. Hannah and Pete would work in the same room with their students and the students would come to the tutoring room from their larger class. Hannah used the proximity to Pete in several of her math focused sessions as an opportunity to collaborate in order to help her students. Below is an example of how Hannah would ask Pete for support in a session.

Hannah was working with a student she had worked with in a previous session. The student told Hannah he needed help understanding angles and Hannah asked Pete for support. Pete gave Hannah support in the form of a notebook resource page that he created about angles. Hannah used the notes as a tool to move her student through the session. At one point in the session, she again asked Pete for a quick definition of an adjacent angle in order to make sure that she was not leading the student in the wrong direction (Observation, 11-24-2014).

Hannah wrote in her reflection log, "I thought the session went really well. We worked on math, specifically finding the area of rectangles and learning about adjacent and interior/exterior angles" (Reflection Log, 11-14-2014). Although Hannah did not specifically reflect on collaborating with Pete during the session, she reflected that the session went well. It is obvious from the observation and field notes that the student was able to understand angles based on the resources provided by Pete that Hannah sought out. 
Pete

Whereas Molly tended to partner with the teacher or other students and Hannah would collaborate directly with Pete, Pete tended to collaborate and share authority directly with his students in sessions. Below is an example of how Pete would partner.

Pete was working on factoring with a student in a session. Pete choose to start the session by asking questions and offered options of how they could work together to solve the problems. The student and Pete discussed which option would work best to solve the problem. Once they agreed on the method they went to work to get the answer, the session progresses (Observation, 12-19-2014).

In his reflection log, Pete wrote, "I taught the student a tree method and a factoring method of multiplication. Through these short lessons, my student was more confident with his math skills which enabled him to complete his coursework more efficiently. We had positive outlooks in the session because we were productive" (Reflection Log, 12-192014). Pete does not mention directly in his reflection $\log$ that he chose to collaborate or partner with his student. He noticed that the session had a positive outcome and used the word "we" in conjunction with productivity. The partnership transaction Pete encouraged at the beginning of the session obviously allowed for both the student and Pete to be productive in the session.

The ability to be a partner instead of being an authority figure in sessions may have helped the tutors develop stronger relationship with their students and teachers within the building. One of the ESL teachers that observed many of the tutoring interactions said:

The tutors that work with the ELLs were friendly and respectful and they gently guided the students through the content. They were really receptive to the students and therefore earned the students respect. It is really important for the urban ELLs that the tutors develop rapport, respect with the students. It is really important that the student did not view the tutor as another authority figure. (Interview, 1-7-2014)

The tutors established the ability to develop partnerships within their sessions and this enabled them to make learning more about having a social interaction which aligns with Vygotsky's (1978) social learning theory. The social learning theory says that a person learns if they are taught by a more capable adult in an environment of social interaction. The tutors established this type of environment through partnerships which allowed learning to happen.

\section{Discussion}

\subsection{Modeling}

There are differences in how the tutors would model. Molly was working with a higher level ELL student and she chose to model how to dissect the questions but did not concentrate on modeling how to read the text. Hannah, who was working with a lower level ELL, chose to model how to read the text, questions, and how to find the answers using the text. It appears that the tutors decided their level of modeling based upon the level of language proficiency the students had. Pete's modeling demonstrated for students how they could check to make sure the answer they were going to pick for the math question was right. He was not modeling how to figure out what the question was or what it was asking like Hannah and Molly. Pete was modeling how to find the right answer by creating a problem based on the question being asked which required the student having background knowledge. By modeling, the tutors were providing a cognitive support to help students learn.

Having background knowledge was an embedded requirement in all of the tutor's modeling techniques. Hannah modeled how you had to use the background of a text to answer a question. Molly modeled how you had to have a background understanding of how questions were worded in order to be able to pick the right answers. Pete modeled how you could figure out the right answer to a Math multiple choice question if you were able to create a problem out of the question being asked which required background knowledge. In this way, all of the tutors were using different modeling techniques but they were also demonstrating the importance of having background knowledge. By modeling how background knowledge is used to answer comprehension questions the tutors were demonstrating one of the aspects of the Sheltered Instruction Observation Protocol (SIOP) model (McIntyre et al., [8]). The positive connection between how having background knowledge increases academic performance and reading comprehension has been documented in the reviewed literature (Anderson and Freebody, [9]; Green and Lynch-Brown, [10]) and the tutors were modeling in their interactions how background knowledge supports learning outcomes.

\subsection{Translation}

Two of the tutors had limited Spanish background and would use simple Spanish phrases in their sessions to help communicate an academic term to their students or to direct them to complete a task. In every session where Molly and Hannah chose to use Spanish terms, students demonstrated more attention and 
understanding. Molly and Hannah were demonstrating traits of bi-lingual education when they used Spanish in their session to help translate concepts which was found in the literature to be an effective practice for ELLs. The ESL teacher noticed this about the tutor's interactions and commented, "It is great to know the language for quick issues. Even if you can explain the directions in Spanish it just helps so much"(Interview, 1-7-2015).

Additionally, all of the tutors functioned as oral translators for their students. They would simplify directions, questions, and reading passages for their students. By being willing and able to break down concepts and simplify, the tutors could help their students understand how to work with a concept. They were able to make the learning experience more like an understandable conversation.

The student could talk to the tutor and ask a question, something they could not do in a written context or in a larger class. A mainstream teacher at the school said:

ELL students need support in their spoken English so that they feel comfortable speaking up and advocating for themselves. They also need to be provided with one-on-one time with adults in their school day to facilitate a level of comfort needed for them to be able to reach out with a question when they struggle in class (Interview, 1-7-2015).

\subsection{Partnership}

The fact that each of the tutors built partnerships within their sessions is an important finding. Hannah, at times, did not have enough background knowledge or recall to teach a skill and she knew this. Instead of leading a student in the wrong direction, she partnered with a fellow tutor to make sure she was able to give her student the right information. Hannah commented, "Working together provided a meaningful learning experience for the student in the sense that if I did not know something they would teach me and vice versa. I also had Pete to help me explain something if I had trouble which was a great resource" (Post-Interview, 12-27, 2015). Molly would partner with teachers or other students to make sure she was able to get her students the right information. Pete chose to partner directly with his students in order to give them more autonomy.

\section{Conclusion}

Each of the tutors would model for students and they were all aware of modeling. Their awareness may have come from the fact that all of the tutors were enrolled in their third year of a pre-service educational program that discussed modeling as a pedagogical tool of good teaching. The fact that they all modeled how to answer multiple choice questions is interesting considering the high stakes testing culture that teachers and students face in public schools. Many of the materials that the students would bring to a session would be in a test taking format. Math problems and reading passages had multiple choice questions with them and the students would be asked to write written responses in a brief constructed response format. One mainstream teacher at the school who sent students regularly to tutoring from his sophomore seminar class talked about the material. He said "The Sophomore Seminar class is designed to assess student's needs in regard to their Keystone performance. We use Acuity on line assessment to build individualized work to help students with the types of questions with which they struggle most" (Interview, 1-7-2015). The tutors were modeling in their sessions how to choose the best answers when given different choices; they were modeling how to take test well.

The tutors were not told to help their students learn how to take tests well. The tutors were told to help students with the material they brought to a session. Additionally, the ability of tutors modeling how to answer multiple choice questions did not come from training they received to become a tutor. This understanding of how to model test taking strategies came from their own experience taking tests in their own educational journey. The tutoring coordinator commented:

The seminar class that we pulled high school ELLs from for tutoring was geared toward helping our students with the state assessments and that class happens all year. We know that the test is an artificial barrier to entry into different academic worlds and opportunities but we also know we need to give our students these skills. We can't ignore that they need to know how to take a test. The mainstream teacher that we worked with to get students is the head of the English department. The seminar teachers get overwhelmed and tutors gave a chance for individualized instruction (Interview, 1-7-2015).

The fact that the sessions reflected modeling in regards to helping ELL learners learn how to take test can be connected to literature that found ELLs currently score 20 to 50 percentage points below L1 learners on standardized tests (Abedi and Dietal, [11]; Government Accountability Office, [1]). In the current culture of standardized testing, the school site was trying to prepare their ELL learners to perform better on the test and this translated into the everyday course material they were interacting with in their content classes.

When tutors provided translation in their sessions, they provided a chance for the ELLs to connect to the material and with the tutor more. The ESL coordinator 
said, "Nothing beats a one-on-one tutoring session. In a one-on-one, students have a chance to bare their souls more. They will be able to tell the tutor that they really don't get something or confide that they don't understand what the teacher is saying and they are not going to do this in a bigger group" (Interview, 1-72015). The ability for tutors to act as translators in their sessions provided their students with a message of caring. They were telling their students through the acts of translation that they understood that reading, writing, and speaking in a second language was challenging. Translating in a session built a bridge for their students between either their $1^{\text {st }}$ and $2^{\text {nd }}$ language or it built bridges between written and spoken English.

Partnering became a way of communicating to the students that the academic experience does not have to be a self-propelled journey. By partnering, the tutors were providing a message to their students that learning comes from social interaction. The tutors demonstrated how they themselves could learn new concepts and ways of teaching as a result of asking a more capable person within a session. Sometimes this person was a fellow tutor, teacher, another student, or the student that was in the session.

The partnership that tutors formed in their sessions also speaks to how they aimed to share authority and responsibility for learning in their sessions. The ESL teacher that observed the students in sessions noticed this partnership interaction. She said, "The tutors that work with the ELLs are friendly and respectful and they gently guide the students through the content. They were really receptive to the students and therefore earned the students respect" (Interview, 1-72015). Partnering versus dictating helped the adolescent ELLs feel more comfortable and therefore they opened up more to the tutor and the content. The partnership finding makes a case for more studies that look at the benefits of collaboration when working with ELL students.

The implications of this study for educators that work with English Language Learners is that they should make sure they are taking the time to model, translate information, and build partnerships for the students that they are supporting through tutoring. The results of this study also call for more studies to be conducted on how tutors are supporting adolescent ELLs in order to help educators in the field understand what practices are working.

\section{References}

[1] U.S. Department of Education, Institute of Education Sciences, National Center for Education Statistics. (2012). Digest of Educational Statistics, 2007 (NCES 2008-022). Retrieved from http://nces.ed.gov. (Access date: $15^{\text {th }}$ August, 2016).
[2] National Survey of Latinos: Education (2004). by The Pew Hispanic Center and the Henry J. Kaiser Family Foundation. Retrieved from http://www.pewhispanic.org/20 04/01/26/2004-national-survey-of-latinos-education/.com (Access date: $15^{\text {th }}$ August, 2016)

[3] August, D. and Shanahan, T (Eds.). (2006). Developing literacy in second-language learners: Report of the National Literacy Panel on Language Minority Children and Youth. Mahwah, New Jersey: Lawrence Erlbaum Associates.

[4] Dynarski, M. and Gleason, P. (1999). How can we help? Lessons from federal drop-out prevention programs. Policy brief. Princeton, NJ: Mathematica Policy Research, Inc. Retrieved from www.mathematica-mpr.com/publications/P DFs/howhelp.pdf. (Access date: $15^{\text {th }}$ August, 2016).

[5] Joftus, S. and Maddox-Dolan, B. (2002, April). Left out and left behind: NCLB and the American high school. Washington, DC: Alliance for Excellent Education.

[6] Biancarosa, G. and Snow, C. (2006). Reading next: A vision for action and research in middle and high school literacy. Washington, DC: Alliance for Excellent Education.

[7] Deshler, D., Palincsar, A. Biancarosa, G., and Nair, M. (2007). Informed choices for struggling adolescent readers: A research-based guide to instructional programs and practices. New York: Carnegie.

[8] McIntyre, E., Kyle, D., Munoz, M., Chen, C.T., and Beldon, S., (2010). Teacher learning and ELL reading achievement in sheltered instruction classrooms: Linking professional development to student development. Literacy Research and Instruction, 49, 334-351.

[9] Anderson, R.C. and Freebody, P. (1981). Vocabulary knowledge. In J. Guthrie (ed.), Comprehension and Teaching: Research Reviews (pp. 77-117). Newark, DE: Reading Association. Washington, D.C.: National Academy of Science.

[10] Greene, B.E. and Lynch-Brown, C. (2002). Effects of teachers' reading aloud styles on vocabulary acquisition and comprehension of students in the early elementary grades. Journal of Educational Psychology, 94, 465-474.

[11] Abedi, J. and Dietal, R. (2004). Challenges in the No Child Left Behind Act for English Language Learners. CREST Policy Brief 1.

[12] U.S. Government Accountability Office. Reported Status of Education Statistics. GAO-12-565R. Published 2006. Retrieved from http://www.gao.gov/products/GAO12-565R. (Access date: $15^{\text {th }}$ August, 2016). 